\title{
Bar press and bar release as avoidance responses
}

DONALD MELTZER, DEPARTMENT OF PSYCHOLOGY, SOUTHERN ILLINOIS UNIVERSITY, Carbondale, Ill. 62901

Four rats were conditioned on a continuous avoidance schedule in which either a bar press or bar release postponed shock for 20 sec. A response produced stimulus was presented while the bar was held down. Mean response duration (RD) was longer than mean interresponse time (IRT) for all four Ss. There was also evidence of temporal discrimination in RD but not in the IRTs.

Many Es have stressed the difficulty of conditioning rats to avoid shock by emitting a bar pressing response. Although conditioning failures have most often been reported in studies of dicriminated avoidance (e.g., Meyer, Cho, \& Weseman, 1959), similar difficulties have been encountered in continuous avoidance experiments (Ellen \& Wilson, 1964; Bolles \& Popp, 1964). Rats which failed to learn the avoidance response were described as freezing, or keeping the bar depressed for a large part of the session. Feldman \& Bremner (1963) reported a study in which they eliminated freezing behavior by shocking the rat for remaining on the bar for more than a few seconds. Under these conditions all their Ss quickly learned the avoidance response. However, this was actually a new type of avoidance experiment in which shock followed either a specified maximum bar holding time or a specified maximum off-bar time.

Keehn (1967a, b) showed that bar-press duration was effectively controlled by the length of the hold-shock interval but did not describe his Ss' stable performances. This experiment examined the bar-press and bar-release patterns of rats' performances when press and release were equally effective in delaying shock.

Subjects. Four Long-Evans, male, 100 day old, hooded rats were the Ss. Food and water were continuously available in each S's home cage.

Apparatus. The experiment was run in a dark, sound damped room into which masking white noise was introduced. Two experimental chambers with stainless steel walls, grid floors, and a Plexiglass ceiling were used. The bar in each chamber was mounted 2 in. above the floor in the middle of the front wall and a $7.5 \mathrm{~W}$ light bulb was located above and to one side of the side wall. Illumination, as measured by a Weston light meter, was approximately $2 \mathrm{ft} / \mathrm{c}$ 1 in. above the center of the grid floor when the light was on.

Procedure. Four hour sessions were scheduled five days a week until a total of 30 sessions had been run. Each $S$ always ran in the same chamber.

The most important difference between this procedure and a typical continuous avoidance experiment was that each bar release, as well as each bar press, postponed shock for 20 sec. During the first session shock was presented continuously beginning $20 \mathrm{sec}$ after the last press or release. Changing the state of the bar (i.e., releasing it if it was being held or vice versa) terminated the shock. In all subsequent sessions shock lasted for 0.5 sec and was presented on a VI $3 \mathrm{sec}$ schedule after $20 \mathrm{sec}$ without either a bar press or bar release. Shock intensity was set at $2.5 \mathrm{~mA}$ on a Lehigh Valley No. 1531 constant current shock generator.

Specific exteroceptive stimuli were associated with the state of the bar. As long as the bar was held, the light was turned off and the chamber was in total darkness. Light remained on when the $S$ was off the bar.

Frequency distributions of response durations (RD) and interresponse times (IRTs) were recorded throughout the experiment. Both distributions had $2 \mathrm{sec}$ bin widths. An IRT was defined as the time from bar release to bar press which is in contrast to the usual practice of defining an IRT as the time between two successive bar presses.

Results. All four Ss learned the avoidance response. Assuming that the VI $3 \mathrm{sec}$ schedule provided maximum shock frequency, the best conditioned S avoided an average of $98 \%$ of the shocks in Session 25-30. The worst conditioned Ss avoided an average of $96 \%$ of the shocks. Expressed another way, there was a range of 21.3 to 45.8 shocks/h for the mean of the individual Ss over the five sessions.

The response data were analyzed in several different ways. Figure 1 shows the frequency distribution of IRTs and RDs in
Session 30 expressed as percentages of all the responses in that session. All four Ss showed a steady decline in the frequency of IRTs as time increased. Only one $\mathrm{S}, \mathrm{HBr}-2$, showed a similar monotonic decline in the frequency of RD as time increased. Mean RD was therefore greater than mean IRT for all of the Ss. And, as that statement implies, all Ss held the bar for more than half the session. These results suggest that Ss may make a temporal discrimination while holding the bar which is not apparent when they are off the bar.

Anger (1956) has pointed out that a frequency distribution may conceal data showing a temporal discrimination since every short IRT (or RD) prevents the possibility of a long IRT (or RD). He argued that a conditional probability measure such as the one shown in Fig. 2 would be more revealing. Figure 2 shows the data from Session 30 replotted as IRTs/opportunity (i.e., the number of occasions on which a $S$ pressed the bar in a 2 sec interval divided by the total number of IRTs that long or longer) and RDs/opportunity (i.e., the number of occasions on which the S released the bar in a $2 \mathrm{sec}$ interval divided by the total number of RDs that long or longer). These conditional probability measures showed that all four Ss learned at least a weak temporal discrimination of RD. An S was least likely to release the bar after 2-4 sec of holding it down and most likely to release the bar after holding it for more than $12 \mathrm{sec}$ or less than $2 \mathrm{sec}$. Three of the four Ss showed a fairly steady decline in the conditional
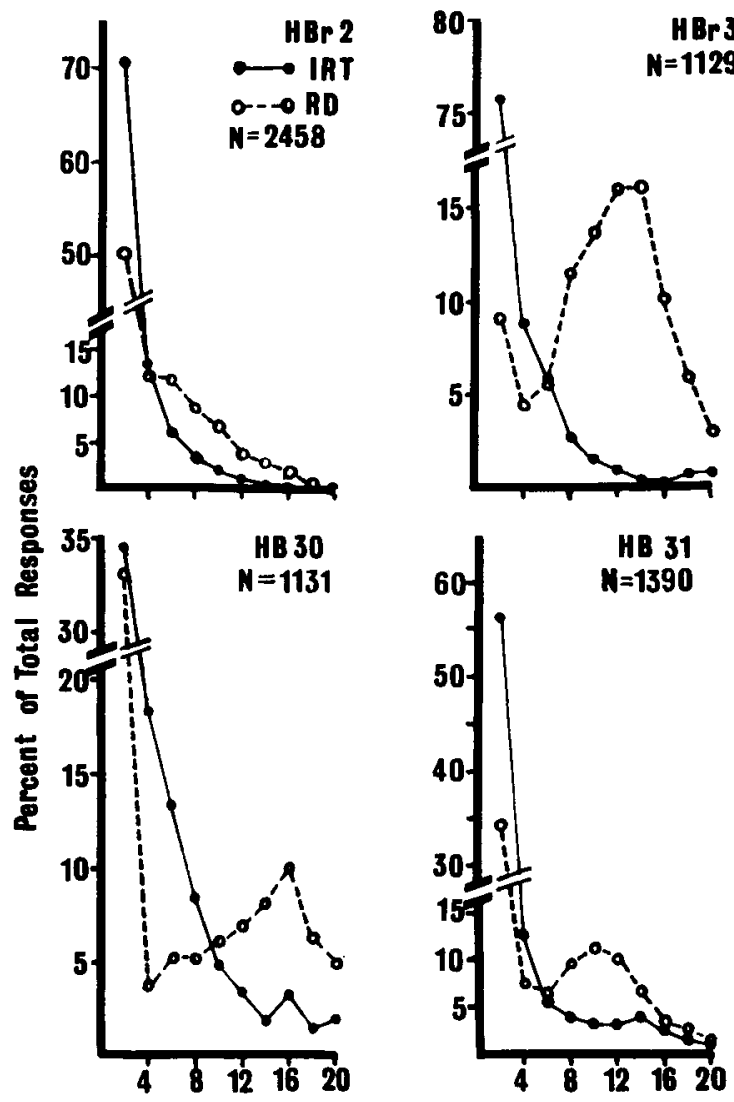

Time (Seconds)

Fig. 1. Frequency distributions of IRTs and RDs in Session 30. IRTs and RDs longer than $20 \mathrm{sec}$ are not shown. $\mathrm{N}$ refers to the total number of bar presses made by $S$. The number of bar presses equals the number of bar releases in a session. 


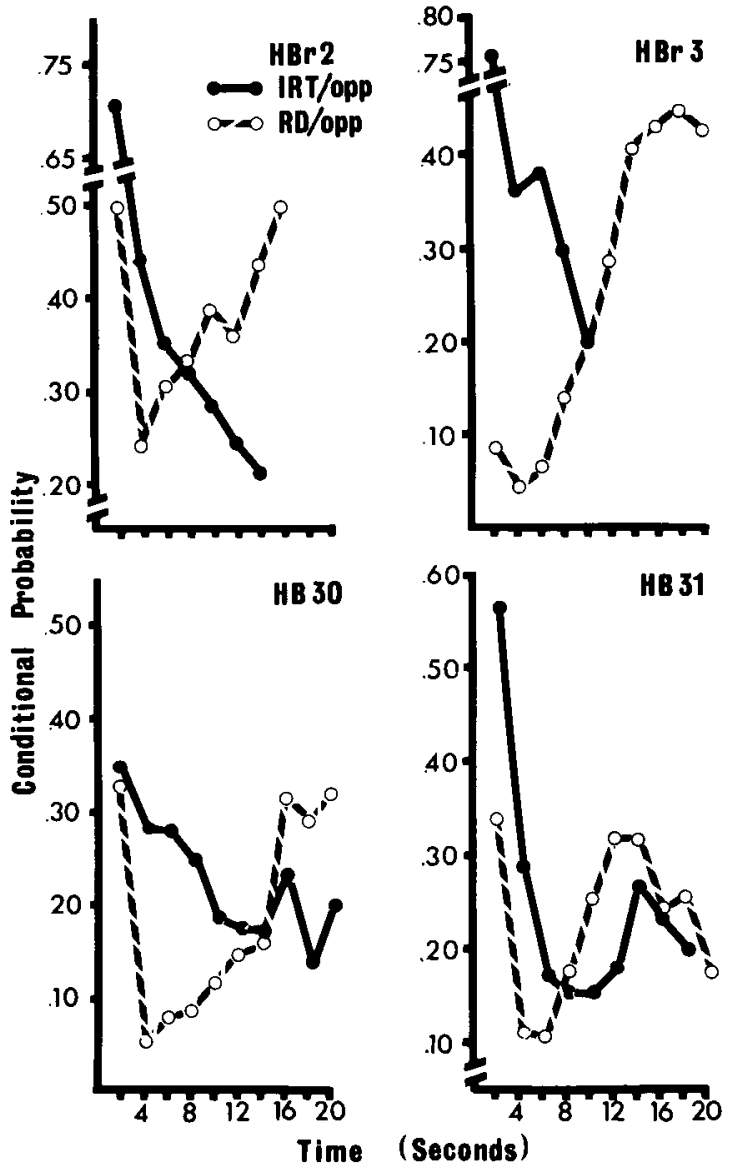

Fig. 2. The conditional probabilities of bar press and bar release in each bin. Conditional probabilities are not shown for bins in which there were less than 20 responses nor for presses or releases which occurred after more than 20 sec.

probability of bar pressing while the fourth S, HP - 31, showed some signs of temporal discrimination.

The data was also examined to see whether Ss received more shocks for failing to release the bar or for failing to press it. Three of the four Ss showed no consistent pattern although a large proportion of the shocks received on any one day might come from only one type of avoidance failure. The fourth $\mathrm{S}, \mathrm{HBr}-2$, invariably received most of its shocks because it failed to press the bar.

Other studies of continuous avoidance have reported a "warm-up" phenomenon which was also apparent when this procedure was used. Readings were taken at $30 \mathrm{~min}$ intervals in each of the last five sessions. All Ss received fewer shocks in the second $1 / 2 h$ of the session than in the first. However, shock frequency often continued to decrease until the third or fourth 30 min segment before reaching the minimal level that was maintained for the rest of the session.

Each S usually, but not invariably, increased its response rate after the first $1 / 2 \mathrm{~h}$ of the session, but there were also important changes in other response characteristics. The per cent of time during which the $S$ held the bar was always higher during the second $1 / 2 \mathrm{~h}$ of the session than during the first, but there was actually a slight reduction in mean RD because Ss less often held the bar until shocked. At the same time the per cent RDs lasting between 10 and $20 \mathrm{sec}$ increased. Mean IRTs also decreased but the only obvious change in the IRT distribution was a reduction in the number of occasions on which Ss failed to press until shocked.

Discussion. Why did all four Ss have longer mean RDs than IRTs? There is probably no single answer to that question since several variables may affect the results. The bars in both boxes were easily accessable and could be held down with little effort. Presumably a less accessable bar, or one which was harder to hold down, would have changed the relationship between mean RD and mean IRT. The response produced stimulus was also an important variable with an unknown effect on the results.

Whatever the variables involved, bar holding was the behavior emitted most often in this experiment. The difficulties so frequently experienced in avoidance conditioning when rats have to make a bar press response may therefore be due to the fact that bar release, rather than bar press, is a difficult response for the rat to acquire. Since bar pressing was a highly probable response soon after bar release a short "release-shock" interval would probably be compatible with successful avoidance conditioning. But an optimal procedure might well include another condition which is generally ignored-a long "press-shock" interval. When the E fails to specify both the press-shock and release-shock intervals the rat may respond to the accidental contingencies its own behavior initially generates.

\section{REFERENCES}

ANGER, D. A. The dependence of interresponse times upon the relative reinforcement of different interresponse times. $J$, exp Psychol., 1956, 52, 145-161

BOLLES, R. C., \& POPP, R. J. Parameters affecting the acquisition of Sidman avoidance. J. exp. Anal Behav., 1964, 6, 315-321.

ELLEN, P., \& WILSON, A. S. Two patterns of avoidance responding. J. exp. Anal Behav., 1964, 7, 97-98.

FELDMAN, R. S., \& BREMNER, F. J. A method for rapid conditioning of stable avoidance bar pressing behavior. J. exp. Anal. Behav., 1963, 6, 393-394.

KEEHN, J. D., \& WEBSTER, C. D. Discriminated Sidman avoidance behavior by guinea pigs. Psychon. Sci., 1967, 7, 315-316.

KEEHN, J. D. Double discrimination bar press and bar release avoidance. Psychon. Sci. 1967, 8, 189-190.

MEYER, D. R., CHO, C., \& WESEMAN, A. S. On problems of conditioning discriminated level-press avoidance response. Psychol. Rev., 1960, 67, 224-228. 